\title{
On the Choice and Linkage of Large Scale Forecasting Models
}

\author{
KAN CHEN
}

\section{ABSTRACT}

Different kinds of large scale forecasting models are compared on the basis of their forecasting time horizons. The choice of model or models should be guided by the decisions to be made. The linkage between models will be facilitated by further developments that will make the models epistemologically compatible. To enhance utilization, the imbedding of forecasting models in some use-oriented framework may be more important than the linkage between models.

\section{Introduction}

Large-scale mathematical models for forecasting purposes have been developed over several decades by a variety of disciplines, notably economics and systems engineering. In the 1975 Workshop on Modeling Large Scale Systems at National and Regional Levels [1], three kinds of modeling techniques were reviewed and compared in the initial discussion: econometrics [2,3], input-output [4,5], and systems dynamics [6,7]. No doubt many other kinds of modeling techniques could be added to the list, and many of them were actually included in the intense subsequent discussion at the Workshop. At times the discussion seemed to get heated and divisive as the question of choice among the various modeling techniques was deliberated. On the other hand, one of the adhesive forces which drew the multi-disciplinary group together in the first place, and which hopefully will continue to do so in the future, was the genuine interest in exploring the feasibility and advantage of linking different models together or fusing different modeling techniques for large scale systems. Some of the ongoing linkage projects, which already show successful preliminary results and will continue as live research activities, are the LINK system for forecasting international trade [8] and the SEAS system for forecasting environmental impacts at national and regional levels [9]. The purpose of this paper is to reflect on the choice and linkage of different types of models and modeling techniques. The rather obvious underlying thought (and conclusion) is that the choice will depend on the ultimate use to which the models will be put, and that the linkage of models will be successful and meaningful only to the extent that the models are epistemologically compatible.

\section{Time Horizon, Utilization, and Epistemology}

The reflection on the choice and linkage of models will be organized on the basis of forecasting time horizon considerations. It will be argued that the time horizon has significant implications of utilization and epistemology.

KAN CHEN is Professor of Electrical and Computer Engineering, University of Michigan, Ann Arbor, Michigan 48104. 
The time horizon of forecasting models can be conveniently divided into short range, intermediate range, and long range. Of course this division of time is only relative with respective to the dynamics of the system being modeled. There are no absolute criteria for demarcation. Conceptually short range forecasting is for the "inertia period" [10] when the momentum of historical and current trends is still prevalent; long range forecasting is for the "control period" [10] when the system structure as well as system variables are subject to deliberate control; and intermediate range forecasting is somewhere in between. In the parlance of the futurist, then, short range forecasting is essentially "exploratory" and long range forecasting "normative" [11].

The ultimate use of forecasting models at national and regional levels is to aid policy decisions at those levels. In constructing and choosing a mathematical model, the salient nature of the policy decisions and the process through which the decisions are made must be well understood [12]. As large scale forecasting models and their linkages can be very unwieldy, expensive to manipulate, and time consuming to construct, it is often imperative, from the standpoint of utilization, to begin with the question of what decisions are to be made rather than the question of what models are available. In other words, the choice of forecasting model or models should be bound or guided by the decisions to be aided.

The manner in which decisions need to be aided is also important. If the emphasis is on the generation of policy options, relatively simple but holistic models can often give better insight to the basic problem (and thus the optimal policy alternatives) than large scale complicated models [13]. It would also help to inbed the forecasting models in a systematic procedure for policy generation [14]. If the emphasis is on the identification of relatively unexpected policy consequences, one should imbed the forecasting models in the kind of procedure typified by technology assessment [15]. If the emphasis is on the quantitative and comprehensive evaluation of policy options and policy consequences already identified, the utilization of forecasting models may be enhanced if they are imbedded in the framework of decision analysis $[16,17]$. The point to be made here is that, for the purpose of utilization, the imbedding of forecasting models in some appropriate overarching use-oriented framework may be more important than the linking of different types of forecasting models.

A mathematical model of social systems, whether for explanatory or for forecasting purposes, is not by itself a reality, but merely a simplified picture of reality that man can understand [2]. However, man has tried to understand social as well as natural phenomena through very different inquiry systems. Inevitably these inquiry systems are reflected in the different epistemological underpinnings. Model builders sometimes find it difficult to accept each other's models, and therefore are very reluctant to have their models linked, because of their very strong and different epistemological commitments.

Five basic inquiry systems, each originated by an illustrious philosopher, have been elucidated by Churchman [18] and summarized by Mitroff and Turoff [19] as follows:

(1) Leibnitz-Truth is analytic; i.e., the truth content of a system is associated entirely with its formal content.

(2) Locke-Truth is experiential; i.e., the truth content of a system is associated with its empirical content.

(3) Kant-Truth is synthetic; i.e., the truth content of a system is not located in either its theoretical or its empirical components, but in both.

(4) Hegel-Truth is conflictual; i.e., the truth content of a system is the result of a 
highly complicated process which depends on the existence of a plan and a diametrically opposed counterplan.

(5) Singer-Truth is pragmatic; i.e., the truth content of a system is relative to the overall goals and objectives of the inquiry.

In the context of forecasting models, econometrics [3] has been anchored primarily on the Lockean inquiry system, emphasizing the use of empirical data. To the extent that econometric models are extended on the basis economic theory, the Kantian approach has been invoked. On the other hand, systern dynamics [7] has followed the Leibnitzian approach, emphasizing the analytic consistency on the basis of a world view held by the model builder. To the extent that model builders of opposite world views use system dynamics to advocate diametrically opposed policies (e.g., no-growth vs. pro-growth) $[20,21]$, the Hegelian inquiry system has been manifested. Finally, the previous arguement for imbedding forecasting models in some overarching procedure to enhance the overall goals of ultimate utilization of models has essentially followed the Singerian approach.

In the remainder of this paper, the time horizon of forecasting models will be used to organize and summarize further reflections on the choice and linkage of models. The considerations of utilization and epistemology will be interwoven with other thoughts in the same organizing framework.

\section{Short Range Forecasting}

Mathematical models are defined by their structures and parameters. For short range forecasting, such as quarterly economic forecasts, a linear approximation is often a sufficiently accurate representation of the structure. Sometimes substantial improvements can be obtained by hypothesizing linear relationships among not the variables themselves, but among the logarithms or some other functions of the variables. Still the basic structure is not much more complicated than some relatively simple deviation from linear simultaneous equations. What makes the mathematical models credible and powerful for short range forecasting is the maximum utilization of empirical or historical data for determining the model parameters. Parametric estimation is based on classical theory of statistical inference, using sampling theory of objective (or frequentistic) probabilities [22]. Uncertainties in the results of such short range forecasting can thus be expressed in terms of confidence intervals. These are all strengths of econometric models and of economic input-output models when the parameters in the latter are estimated strictly on the basis of actual data.

As pointed out previously, short range forecasting models are essentially for "exploratory forecasting." The decisions to be evaluated with the aid of this kind of models are changes of policy variables, assuming no changes of the socio-economic structure. For example, the impact of national fiscal policies on inflation and unemployment may be assessed quantitatively in the short run with the aid of econometric models.

It appears that the extension of short range forecasting models would be most productive in the direction of linkage among different models that share the same epistemological underpinning of the Lockean inquiry system. These composite models may be based on the same discipline but different scopes (such as linkages between national economic models [8] or based on different disciplines (such as linkages between economic models and demographic models [23]. More sophisticated modeling approach within essentially a single discipline is also needed, such as the inclusion of consumer 
confidence, based on consumer survey research [24], as an additional crucial variable in econometric models. The emphasis on the use of large samples and empirical data will make all these approaches epistemologically compatible, and therefore the linkages between their corresponding models relatively free to conceptual problems.

\section{Intermediate Range Forecasting}

As we try to extend the time horizon of forecasting modes to the intermediate range, we will have to include the forecasts of some parameter changes and some lowerlevel structural changes in the models. A typical example would be the forecast of coefficient changes in economic input-output models. Such forecasts would be based on the considerations of technological development, relative prices of competitive materials and processes, and the dynamics of competitive substitution in the future [4]. The analysis will be based on engineering-economic theories and sometimes even on experts' judgments rather than on observable data alone. Uncertainties in the results of such intermediate forecasting can still be expressed in terms of probabilities. However, these will be subjective (or personal) probabilities rather than observable data, but the inference also includes in its calculus prior probabilities which are subjective. In other words, the statistics being used here is Bayesian rather than classical [22].

Since intermediate range forecasting models include parametric and lower level structural changes, they are more prescriptive in suggesting basic solutions to socio-economic problems, although the validity of the prescription may seem less credible than that in short range forecasting models. For example, the U.S. energy model used by the Federal Energy Administration [25] led to the suggestion of petroleum price support through excise tax in order for the U.S. to achieve a high degree of energy independence within 10 years. Aside from the value implications, the effectiveness of the specific excise tax policy to reduce oil consumption hinges on the forecast of the price elasticity that is not based on historical or observable data [26].

An active and fruitful direction of further work for intermediate range forecasting models is the linkage between models which are epistemologically compatible. As hinted previously, the extension from the Lockean to the Kantian inquiry systems may be conceptually less problematical than the fusion between the Lockean and the Leibnitzian inquiry systems. It should also be easier to link models based on similar disciplines than models based on unrelated disciplines. Following this line of thought, the linkage between econometric models based on historical data and input-output models based on engineering projections of coefficient shifts should be tried first. Given success in this attempt, the composite economic model can then be extended to include, say, environmental models based on experts' judgment of long range environmental impacts of specific economic activities. This strategy of model development has been illustrated by the SEAS model [9] of the Environmental Protection Agency. Further work should also be done to revise and update experts' judgment on the basis of new data, new research results, and outcomes of deliberate social experiments [27] or quasi-experiments [28].

\section{Long Range Forecasting}

Needless to say, long range forecasting for social systems is most difficult, for so many fundamental structural changes in human and social behaviors can take place, given sufficient time for basic shifts in social values and social policies. And there is no time-proven theory of long range social change. It may be effectively argued that long 
range forecasting is largely normative, instead of exploratory. That is, we can only forecast the possible paths which society can follow to reach certain goals. Each possible path will be an alternative future scenario based on different assumptions of basic value shifts and structural shifts of the society. Of course, the controversy remains as to whether these assumptions could be made and what specific policies could be implemented to make these assumptions true.

To simulate fundamental changes in human and social behaviors under various conditions, the structure of long range forecasting models is likely to be nonlinear and complicated by many feedback paths. The estimation of the parameters is likely to be very difficult because the uncertainties in the parameters will increase rapidly with the time horizon. Moreover, historical data can provide little clue to the parametric values either because the data do not exist within the wide range of operation, or because historical data operating under past or current structures have little meaning for future structures. The result of these difficulties is that long range forecasting models tend to be very subjective. This has been typified by the use of system dynamics to model the entire world [20]. However, this should not be considered bad as long as the subjective judgments are not hidden, for three kinds of judgments-reality, value, and instrumental judgments-underlie all social making processes. The normative nature of long range social forecasting puts a different light on the possible use of the forecasting model. By describing a possible path to some desirable state of future society, modeling can become an instrument for advocating and implementing social change. In this case, forecasting becomes a self-fulfilling prophecy. Similarly, if and when certain forecasting models, such as the World Dynamics [20] and its extensions were widely accepted, the world community would behave in such a manner that the disaster predicted by the World Dynamics model would be avoided [29]. In this case, forecasting becomes a self-defeating prophecy. The kind of decisions tested or influenced by long range forecasting models is thus in the realm of macro structure and value changes.

Extensions of long range forecasting models may take many directions. One direction would be to explicate the high uncertainties in long range forecasting [30]. This can be done by assigning subjective probabilities not only to the uncertain parameters but also to the uncertain events which, if they do occur, will have significant impacts on the structure as well as the parameters of the model. Probabilistic system dynamic modeling is an example of this approach [31]. Another direction would be the attempt to utilize a combination of empirical data, theoretical analysis and experts' judgment (in descending order of priority) as the basis for parametric estimation. Much of the improvement over the World Dynamics Model seems to have followed this direction [32,33]. The thrust in this direction will make the linkage easier between long range and intermediate range models as their epistemological underpinnings will both shift toward the Kantian inquiry system. Still another direction is the use of system dynamic models to explicate the differences in values of world views of disparate social groups, as a basis for Paretian Analysis [34].

\section{Summary and Conclusions}

The following table summarizes the comparison of short range, intermediate range, and long range forecasting models.

The choice of forecasting model or models should be guided by the kind of decisions that the model is intended to aid ultimately. The linkage between different forecasting models will be facilitated by further developments that will make the models epis- 
TABLE 1

\begin{tabular}{llll}
\hline & \multicolumn{1}{c}{$\begin{array}{c}\text { Short } \\
\text { range }\end{array}$} & $\begin{array}{l}\text { Intermediate } \\
\text { range }\end{array}$ & \multicolumn{1}{c}{$\begin{array}{c}\text { Long } \\
\text { range }\end{array}$} \\
\hline $\begin{array}{l}\text { Structure } \\
\text { Parameters }\end{array}$ & $\begin{array}{l}\text { Mostly linear } \\
\text { Historical } \\
\text { data }\end{array}$ & $\begin{array}{l}\text { Feedback } \\
\text { Theoretical } \\
\text { projections }\end{array}$ & $\begin{array}{l}\text { Nonlinear feedback } \\
\text { Educated guesses }\end{array}$ \\
Uncertainties & $\begin{array}{l}\text { Classical } \\
\text { statistics }\end{array}$ & $\begin{array}{l}\text { Bayesian } \\
\text { statistics }\end{array}$ & Highly uncertain \\
& $\begin{array}{l}\text { Policy } \\
\text { variables }\end{array}$ & $\begin{array}{l}\text { Lower-level } \\
\text { structure } \\
\text { changes }\end{array}$ & $\begin{array}{l}\text { Value and macro } \\
\text { structure } \\
\text { changes }\end{array}$ \\
Nature & $\begin{array}{l}\text { Mostly } \\
\text { exploratory }\end{array}$ & $\begin{array}{l}\text { More } \\
\text { prescriptive }\end{array}$ & $\begin{array}{l}\text { Mostly normative } \\
\text { Future Work }\end{array}$ \\
$\begin{array}{l}\text { Interdisci- } \\
\text { plinary } \\
\text { empirical } \\
\text { model } \\
\text { linkages }\end{array}$ & $\begin{array}{l}\text { Mixing } \\
\text { theoretical } \\
\text { and empirical } \\
\text { projections }\end{array}$ & $\begin{array}{l}\text { Explication of } \\
\text { ancertainties } \\
\text { and values }\end{array}$ \\
\hline
\end{tabular}

temologically compatible. However, as pointed out earlier in the paper, the imbedding of forecasting models in some use-oriented framework (be it decision analysis, technology assessment, or policy generation) may be more important than the linkage between models.

1. Workshop on Modeling Iarge Scale Systems at National and Regional Levels, held at Brookings Institution, Washington, D.C., February 10-12, 1975 (sponsored by Massachusetts Institute of Technology under a grant from the National Science Foundation).

2. Klein, L. R., The Fconometric Fxperience (mimeo.), paper presented at the Workshop in [1] .

3. Klein, L. R., $A$ Textbook of Econometrics, Row \& Peterson, 1953.

4. Almon, C., et al., 1985 Interindustry Forecasts of the American Economy, Lexington Bks., 1974.

5. Lenntief, W., Input Output Economics, Oxford University Press, 1966.

6. Henize, J. A Framework for the Evaluation of Large-Scale Social System Models, (mimeo.), paper presented at the Workshop in [1].

7. Forrester, J. W., Principles of Systems, Wright-Allen Press, 1968.

8. Johnson, K. and L. R. Klein, LINK Model Simulations of International Trade: An Evaluation of the Effects of Currency Realignment, J. Finance, 29 (2) (1974).

9. WERC, USEPA, Strategic Environmental Assessment System (SEAS) Phase II, Final Report, June 1974.

10. Platt, J., How Men Can Shape Their Futures, Futures (March, 1971).

11. Jantsch, E., Technological Forecasting in Perspective, OECD (Paris), (1967).

12. Widner, R. R., comments on the Workshop in [1] from a user's point of view, correspondence to T. B. Sheridan, Workshop co-chairman, February 12, 1975.

13. Athans, M. and G. C. Chow, Introduction of Stochastic Control Theory and Economic Systems, Annals of Social and Economic Measurement, 1 (1972).

14. Lasswell, H., A Preview of Policy Sciences, American Elsevier, 1971.

15. Berg, M. R., K. Chen, and G. J. Zissis, Technology Assessment Methodologies in Perspective, in Perspectives on Technology Assessment, ed. by Arnstein and Christakis, The Academy for Contemporary Problems (Columbus), 1975.

16. Raiffa, H., Decision Analysis, Addison-Wesley, 1968.

17. Decisions and Designs, Inc., Handbook for Decision Analysis, (McLean, Va.), 1973. 
18. Churchman, C. W., The Design of Inquiring Systems, Basic Books, 1971.

19. Mitroff, I. I. and M. Turoff, Technological Forecasting and Assessment: Science and/or Mythology? Technological Forecasting and Social Change, 5 (1973).

20. Forrester, J. W., World Dynamics, Wright-Allen Press, 1971.

21. Boyd, R., World Dynamics: A Note, Science, 177, 516-519, (Aug. 11, 1972).

22. Hays, W. L. and R. L. Winkler, Statistics, Holt, Rinehart and Winston, 1970.

23. Lee, R. D., The Formal Dynamics of Controlled Populations and the Echo, the Boom and the Bust, Demography, 11 (4) (1974).

24. Lansing, J. B. and J. N. Morgan, Economic Survey Methods, Institute for Social Research (Ann Arbor), 1971.

25. Federal Energy Administration, Project Independence, (esp. Ch. 8), November, 1974.

26. Resources for the Future, Toward a National Energy Policy, Resources, (48), (Jan., 1975).

27. Rieck, H. W. and R. F. Boruch (ed.) Social Experimentation, Academic Press, 1974.

28. Gage, N. L. (ed.), Experimental and Quaskexperimental Design for Research, Rand McNally, 1966.

29. Chen, K., An Evaluation of Forrester-Type Growth Models, IEEE Trans. on Systems, Man, and Cybernetics, November, 1973.

30. Chen, K. and W. L. Garrison, Urban Modeling, in Urban Dynamics: Extensions and Reflections, ed. by Chen, San Francisco Press, 1972.

31. Gordon, T. J., The Nature of Unforeseen Development (esp. the section on Probabilistic System Dynamics), in The Study of the Future: An Agenda for Research, The Futures Group (Glastonbury, Conn.), 1974.

32. Meadows, D. L. and D. H. Meadows (ed.) Toward Global Equilibrium: Collected Papers, WrightAllen Press, 1973.

33. Mesarovic, M. (ed.), Multilevel Systems Model for Interactive Mode Policy Analysis in Pollution Control-I, Case Western Reserve University, May, 1973.

34. Chen, K., Prolegomenon to Value-Oriented Social Systems Analysis, Battelle Memonial Institute Seminar Paper, 1970.

Reccived 9 April 1975 